\title{
Assessing ectasia susceptibility prior to LASIK: the role of age and residual stromal bed (RSB) in conjunction to Belin-Ambrósio deviation index (BAD-D)

\author{
Avaliação de suscetibilidade para ectasia antes \\ de LASIK: o papel da idade e do leito estromal residual \\ em conjunto ao índice Belin-Ambrósio (BAD-D)
}

Renato Ambrósio Jr ${ }^{1,2}$, Isaac Ramos ${ }^{1}$, Bernardo Lopes ${ }^{1}$, Ana Laura Caiado Canedo ${ }^{1}$, Rosane Correa ${ }^{1}$,

Frederico Guerra'; Allan Luz ${ }^{1,2}$, Francis W. Price Jr ${ }^{3}$, Marianne O. Price ${ }^{3}$, Steven Schallhor ${ }^{4}$, Michael W. Belin ${ }^{5}$

\begin{abstract}
Purpose: To compare the ability to detect preoperative ectasia risk among LASIK candidates using classic ERSS (Ectasia Risk Score System) and Pentacam Belin-Ambrósio deviation index (BAD-D), and to test the benefit of a combined approach including BAD-D and clinical data. Methods: A retrospective nonrandomized study involved preoperative LASIK data from 23 post-LASIK ectasia cases and 266 stable-LASIK (follow up > 12 months). Preoperative clinical and Pentacam (Oculus; Wetzlar, Germany) data were obtained from all cases. Mann-Whitney's test was performed to assess differences between groups. Stepwise logistic regression was used for combining parameters. The areas under the Receiver Operating Characteristic (ROC) curves (AUC) were calculated for all parameters and combinations, with pairwise comparisons of AUC (DeLong's method). Results: Statistically significant differences were found for age, residual stromal bed (RSB), central corneal thickness and BAD-D ( $<<0.001)$, but not for sphere, cylinder or spherical equivalent $(p>0.05)$. ERSS was 3 or more on 12/23 eyes from the ectasia group (sensitivity $=52.17 \%$ ) and $48 / 266$ eyes from the stable LASIK group (18\% false positive). BAD-D had AUC of 0.931 (95\% CI: 0.895 to 0.957), with cut-off of 1.29 (sensitivity = 87\%; specificity = 92.1\%). Formula combining BAD-D, age and RSB provided 100\% sensitivity and $94 \%$ specificity, with better AUC (0.989; $95 \%$ CI: 0.969 to 0.998 ) than all individual parameters ( $p>0.001)$. Conclusion: BAD-D is more accurate than ERSS. Combining clinical data and BAD-D improved ectasia susceptibility screening. Further validation is necessary. Novel combined functions using other topometric and tomographic parameters should be tested to further enhance accuracy.
\end{abstract}

Keywords: Keratomileusis, laser in situ/adverse effects; Dilatation, pathologic/etiology; Corneal diseases/etiology; Corneal topography

\footnotetext{
1 Instituto de Olhos Renato Ambrósio, Rio de Janeiro (RJ), Brazil;

${ }^{2}$ Departmento de Oftalmologia, Universidade Federal de São Paulo (SP), Brazil;

${ }^{3}$ Price Vision Group, Indianápolis, USA;

${ }^{4}$ Departamento de Oftalmologia, Universidade da Califórnia, São Francisco, Califórnia;

${ }^{5}$ Departmento de Oftalmologia, Universidade do Arizona, Tucson, USA.
}

Dr. Ambrósio and Dr. Belin são consultores da Oculus (Wetzlar, Germany)

Dr. Schallhorn é consultor da Abbott Medical Optics (Santa Clara, USA)

The authors declare no conflicts of interest

Receceived for publication on 02/10/2013 - Accepted for publication on 11/11/2013 


\section{ReSUMO}

Objetivo: Comparar a capacidade de detectar risco de ectasia no pré-operatório de LASIK usando o clássico ERSS (Ectasia Risk Score System) e índice Belin- Ambrósio (BAD- D) do Pentacam; e para testar o benefício de uma abordagem combinada, incluindo BAD-D e dados clínicos. Métodos: Estudo não randomizado retrospectivo envolveu dados pré-operatórios de LASIK de 23 casos que evoluíram para ectasia pós-LASIK e 266 casos estáveis após LASIK com acompanhamento mínimo de 12 meses. Dados préoperatórios clínicos e do Pentacam (Oculus, Wetzlar, Alemanha) foram obtidos para todos os casos. O teste de Mann-Whitney foi realizado para avaliar as diferenças entre grupos. Regressão logística foi utilizada para combinar parâmetros. As áreas sob as curvas Receiver Operating Characteristic (ROC; AUC) foram calculadas para todos os parâmetros e as combinações. Comparações de pares das AUC foram realizadas com método de DeLong. Resultados: Foram encontradas diferenças estatisticamente significativas para a idade, residual leito estromal (RSB), espessura corneana central e BAD- D (p <0,001), mas não para a grau esférico, cilindro ou equivalente esférico ( $p>0,05)$. ERSS foi de três ou mais em 12/23 olhos do grupo ectasia $($ sensibilidade $=52,17 \%$ ) e 48/ 266 olhos do grupo LASIK estável (18\% falso positivo). BAD- D teve AUC de 0,931 (IC 95\%: 0,895-0,957), com corte de 1,29 ( ensibilidade $=87 \%$, especificidade $=92,1 \%$ ). A fórmula que combinou BAD-D, idade e RSB, gerou $100 \%$ de sensibilidade e especificidade de 94\%, com melhor AUC (0,989, IC 95\%: 0,969-0,998) do que todos os parâmetros individuais (p>0,001). Conclusão: BAD-D é mais preciso do que ERSS. Combinações de dados clínicos e os BAD-D melhorou a capacidade de identificação de suscetibilidade para ectasia. Uma validação adicional é necessária. Novas funções combinadas usando outros parâmetros topométricos e tomográficos devem ser testadas para melhorar ainda mais a precisão.

Descritores: Ceratomileusis assistida por excimer laser in situ/efeitos adversos; dilatação patológica/etiologia; doenças da córnea/etiologia; Topografia da córnea

\section{INTRODUCTION}

$\mathbf{K}$ eratectasia or progressive "iatrogenic" ectasia after laser vision correction (LVC) was first reported in 1998 by Seiler ${ }^{(1)}$, and rapidly became recognized as a very severe complication of LVC procedures ${ }^{(2)}$. Major attempts for understanding ${ }^{(3)}$ and preventing keratectasia have been taken ${ }^{4}$. Screening for cases at high risk or susceptibility for biomechanical failure and ectasia progression after LVC represents a major challenge for refractive surgeons ${ }^{(5-7)}$. The role of Placido discbased corneal topography and central corneal thickness (CCT) for screening refractive candidates is well recognized ${ }^{(8)}$. However, cases with unexplained ectasia based on such classic methodology have been reported $\mathrm{d}^{(9-11)}$.

Different risk scoring systems were proposed for facilitating the prediction of patients who are at risk of ectasia progression after LASIK. Randleman and coworkers developed the ectasia risk score system (ERSS) based on a retrospective case-control study that integrated corneal topography with refractive correction, residual stromal bed (RSB) and patient's age ${ }^{(13)}$. The ERSS was validated by a second study ${ }^{(14)}$, which confirmed abnormal corneal topography and age as the most important variables for predicting ectasia risk Even though the ERSS represented an advance on the ability to detect ectasia risk $^{(15)}$, there were still $8 \%$ of false negatives, and $6 \%$ of false positives in the original studies. The subjective nature of the classifications of corneal topography limits the repeatability of the approach ${ }^{(16)}$, which may help explain up to $25 \%$ of false negatives in an independent retrospective study of ectasia cases $^{(17)}$. In addition, over $50 \%$ of false positives may occur if a young population of stable LASIK patients is evaluated. Therefore, there is an undisputable need for improving both the sensitivity and specificity of LVC screening for ectasia risk?

"Corneal tomography" enables the evaluation of the front and back surfaces of the cornea along with pachymetric mapping ${ }^{(20)}$. While different technologies are available in many instruments ${ }^{(21)}$, validated criteria for diagnostic interpretation and proper understanding of the generated data is fundamental for the clinician take full advantage of the technology. Along with the description of corneal thickness profile, we introduced the concept of relational thickness, which considers the thinnest value in relation to the rate of increase in thickness towards the periphery ${ }^{(22)}$. Elevation tomography, which has been pioneered and further developed by Belin ${ }^{(26)}$, in combination with comprehensive tomographic thickness evaluation were combined for the development of the Belin/Ambrósio Enhanced Ectasia Display (BAD). The BAD, available on the Pentacam (Oculus, Wetzlar, Germany) software, provides the "d" values which refer to the standard deviation from normality for multiple parameters. The combination of the "d" values, using logistic regression analysis for optimizing separation of normals and keratoconus provide the Belin-Ambrósio Deviation index (BAD-D) value ${ }^{(5)}$. The BAD-D has been demonstrated to significantly enhance the ability to detect ectasia and its susceptibility, as well as to augment specificity to exclude ectasia in suspicious cases ${ }^{(5,6)}$.

The current study was designed to evaluate the ability of standard methods for screening ectasia risk in comparison to BAD-D, as well as to test the benefit of adding clinical parameters to the BAD-D for a logistic regression analysis with the goal of improving accuracy for detecting preoperative ectasia susceptibility among LASIK candidates.

\section{Methods}

The current retrospective study followed the tenets of the Declaration of Helsinki and was approved by the IRB (Institutional Review Board) and Human Ethics Committee from Price Vision Group (PVG, Indiana, USA) and Universidade Federal de São Paulo (UNIFESP, SP, Brazil).

The data from 23 eyes that developed progressive corneal ectasia after LASIK was retrieved from an international pool. For study purposes, the origin of these cases remained anonymous. The data from 266 eyes with documented stability after LASIK after minimal follow up of 1 year was prospectively collected at the Price Vision Group (Indianapolis, USA). The collection of data at the PVG for this study was partially funded by ASCRS (American Society of Cataract and Refractive Surgery) Foundation.

Preoperative clinical parameters from all cases were tabulated in an Excel (Microsoft; Redmond, USA) spreadsheet. 
Age, manifest refraction (sphere, cylinder and axis), spherical equivalent (SE), distance corrected visual acuity (DCVA), LASIK flap characteristics (predicted flap thickness and method for creation), maximal ablation depth, predicted residual stromal bed (RSB), corneal central thickness (CCT), and subjective classification of corneal topography were collected from all cases. Subjective classification was performed by an independent fellowship trained refractive surgeon who did not know the outcome of LASIK in a similar method as described by Ramos and coworkers ${ }^{(16)}$. The RSB was calculated considering the preoperative thinnest value from Pentacam measurements, maximal ablation depth and estimated flap thickness. The Ectasia Risk Score System (ERSS) was calculated according to the original description by Randleman and coworkers.

The U12 files containing the raw data from preoperative Pentacam HR (Oculus; Wetzlar, Germany) were obtained, so that the BAD-D value (version 3) and thinnest pachymetric data were computed from all cases using Pentacam software 1.19r07.5 The BAD-D was not available for the preoperative evaluation of all cases in this study.

Statistical analysis was accomplished using BioEstat 5.0 (Instituto Mamirauá, Amazonas, Brazil) and Med-Calc 11.1 (MedCalc Software, Mariakerke, Belgium). Non-parametric Mann-Whitney U test (Wilcoxon rank-sum test) was used for assessing whether each variable had different distributions among the groups. Stepwise logistic regression analysis was used for combining BAD-D and clinical parameters for augmenting accuracy in separating the cases that developed ectasia from those with stable LASIK outcomes. Receiver operating characteristic (ROC) curves were calculated for all parameters and functions for testing the overall predictive accuracy (cut off, sensitivity and specificity) and calculating the area under the curve (AUC). Pairwise comparisons of the ROC curves were performed to test whether significant differences were present between the AUC among the different parameters for using DeLong method. A $p$ value lower than 0.05 was considered as statistically significant.

\section{RESULTS}

\section{Group characteristics}

The clinical data for the post-LASIK ectasia and stableLASIK groups is summarized in table 1 . Statistically significant differences between groups were found for preoperative age, CCT and BAD-D, as well as for the estimated postoperative RSB (Mann-Whitney, $\mathrm{p}<0.001$ ), but not for preoperative manifest refraction data (sphere, cylinder and spherical equivalent; Mann-
Table 1

Clinical parameters in ectasia and stable cases after LASIK

\begin{tabular}{lcc}
\hline Parameters & \multicolumn{2}{c}{ Mean (range) } \\
\cline { 2 - 3 } & Ectasia cases $(\mathbf{n = 2 3})$ & Stable cases $(\mathbf{n = 2 6 6})$ \\
\hline Age (years) & $26(20$ to 48$)$ & $44(19$ to 66$)$ \\
MRSE $(\mathrm{D})$ & $-3.94(-7.8$ to -0.75$)$ & $-3.09(-8.5$ to 4.1$)$ \\
CCT $(\mu)$ & $514(473$ to 546$)$ & $554(479$ to 664$)$ \\
\hline
\end{tabular}

CCT: central corneal thickness; D: diopters; RSB: residual stromal bed thickness; $\mu$ : microns; MRSE: manifest refraction spherical equivalent

Whitney, $\mathrm{p}>0.05$ ). Time between LASIK procedure and ectasia diagnosis ranged from 3 to 18 months, with an average of 6.1 months. Average follow up of stable LASIK cases was 20 months, ranging from 12 to 49 months (standard deviation $[\mathrm{SD}]=0.61$ ).

In the post-LASIK ectasia group, the flap was created with a Moria OUP microkeratome (Antoine, France) in 7 cases $(30 \%)$ and with a femtosecond laser (Intralase FS 60; Abbott Medical Optics, Santa Clara, USA) in 16 cases (70\%). Only two cases from the ectasia group $(8.7 \%)$ had an Oculus TKC with keratoconus detection; one case was classified as possible and the other as keratoconus grade 1 . Twelve cases (52\%) were classified as moderate to high risk based on an ERSS score of 3 or greater. All ectatic cases had preoperative distance corrected visual acuity (DCVA) equal or better than 20/30. No case had any preoperative slit lamp sign typical of keratoconus.

In the stable LASIK group, a femtosecond laser (Intralase FS 60) set for a 115- $\mu$ m flap depth was used in all cases. Eighteen eyes $(6.77 \%)$ had an Oculus TKC classification as abnormal and 48 of 266 cases (18\%) were classified as moderate to high risk based on the ERSS (score of 3 to 6).

\section{Predictive models}

Table 2 summarizes the ROC results for the parameters which had statistical significant different distributions among the groups. The area under the ROC curve (AUC) for the parameters which did not reach statistical significant differences tend to demonstrate a $50 \%$ chance of positivity, which implies this is a random finding. For example, the distribution of sphere (Sph) was not statistically different within ectatic and stable LASIK cases, with an AUC of 0.566 (95\% CI: 0.507 to 0.624). The ERSS was equal or higher than 3 on 12 eyes from the ectasia group (sensitivity $=52.17 \%$ ) and on 48 eyes from the stable LASIK group ( specificity $=81.95 \%$ ). The best cut off value for BAD-D was 1.29 , with sensitivity of $87 \%$ and specificity of 92.1

Table 2

Parameters extracted from pentacam exam and receiver operating characteristic (ROC) curve analysis

\section{Evaluated parameters}

Clinical parameters

Age

RSB

CCT

ERSS

Belin/Ambrósio deviation value (BAD-D)

Combination of age, RSB and BAD-D

\section{ROC analysis}

\begin{tabular}{|c|}
\hline Cut off \\
\hline$<32.504$ \\
\hline$<349$ \\
\hline$<523$ \\
\hline$>=3$ \\
\hline $\begin{array}{c}>1.29 \\
>0.068\end{array}$ \\
\hline
\end{tabular}

AUC
0.902
0.817
0.824
0.815
0.931
0.989

$\begin{array}{cc}\text { Sens } & \text { Spec } \\ 80.5 & 95.7 \\ 81.2 & 69.6 \\ 84.2 & 65.2 \\ 52.17 & 81.95 \\ 92.1 & 87.0 \\ 100 & 94\end{array}$

$95 \%$ CI

0.862 to 0.934

0.767 to 0.860

0.776 to 0.867

0.766 to 0.858

0.895 to 0.957 0.969 to 0.998 
Table 3

Formula for ESS-I: combined parameter based
on age, RSB and BAD-D

\begin{tabular}{cc} 
Variable & Coefficient \\
\hline Age & -0.17395 \\
RSB & -0.048294 \\
BAD-D & 3.34502 \\
Constant & 16.41 \\
\hline
\end{tabular}

(AUC $=0.931 ; 95 \% \mathrm{CI}: 0.895$ to 0.957$)$. BAD-D was more accurate than all clinical parameters ( $p>0.001$, DeLong's method). Figure 1 represents the interactive dot diagram of the BAD-D, allowing for the visualization of the overlap between groups.

The model that combined BAD-D, age and RSB achieved $100 \%$ sensitivity and $94 \%$ specificity, with a statistically better AUC (0.989; 95\% CI: 0.969 to 0.998$)$ than individual parameter models or the ERSS ( $p>0.001$, DeLong's method). The inclusion of CCT, sphere, cylinder or spherical equivalent did not improve accuracy in the regression analysis. The coefficient and constants for the model which combined age, RSB and BAD-D are listed on table 3 . For making this into a binary parameter, the natural logarithm (ln) of the logistic regression model is calculated. Interactive dot diagrams were used to visualize the clinical performance of the combined parameter (figure 2).

The ROC curves of the parameters which had statistical significant different distributions among the groups are included in figure 3.

\section{Discussion}

This study evaluated the ability of different methods to predict ectasia risk among LASIK candidates. The lack of sensitivity of "classic" methodology based on corneal topography, central thickness and clinical parameters is demonstrated by the fact that the ERSS failed to detect ectasia risk in $47.8 \%$ of post LASIK ectasia cases. However, the ERSS depends on the subjective classification of corneal topography curvature maps, which may vary tremendously among different experts ${ }^{(16)}$. In fact, retrospective evaluation of the preoperative topography of cases that developed ectasia tends to be very rigorous with a high sensitivity if the evaluator knows about the outcome. However, in this study, the topographic classifications were done without the evaluator knowing the outcome of the LASIK procedure.

The BAD-D combined the deviation indices using a linear regression analysis that best separated normals and keratoconic cases5. BAD-D demonstrated excellent accuracy for detecting keratoconus with AUC higher than 0.99 in different studies ${ }^{(5,6)}$. This study found BAD-D to have a significantly higher accuracy for separating the preoperative status of stable-LASIK from the ones who developed ectasia, in agreement with previous studies that evaluated the ability of BAD-D to detect milder forms of ectasia or its predisposition. In a study comprised of 47 eyes with forme fruste keratoconus (FFKC), defined as the fellow eye with relatively normal topography from patients with very asymmetric keratoconus, the cut off of 1.22 led to $93.62 \%$ sensitivity. In that study, FFKC cases were compared to 331 normal eyes randomly selected from normal patients, with AUC of 0.975 and specificity of $94.56 \%$. Interestingly, the cut off value of 1.29 found in the

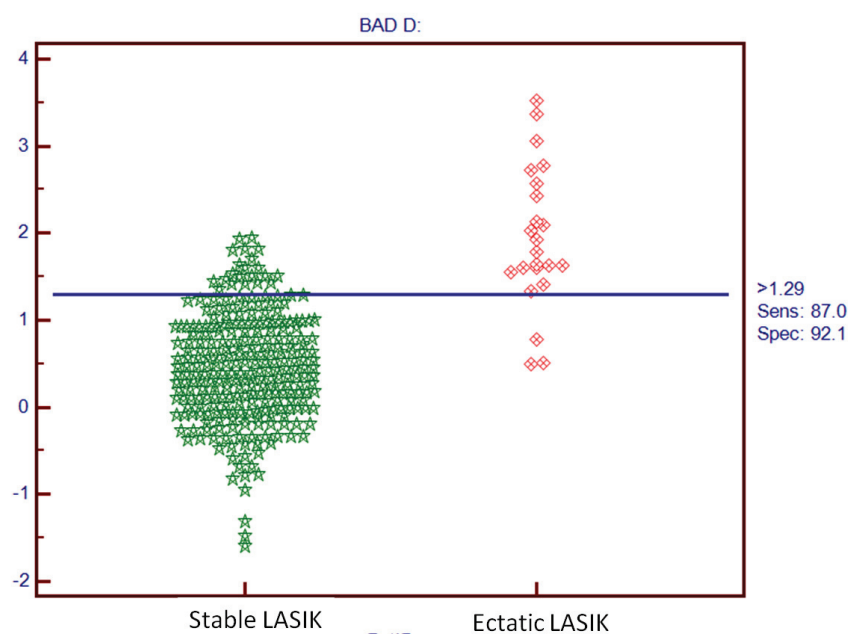

Figure 1: Dot diagram for BAD-D

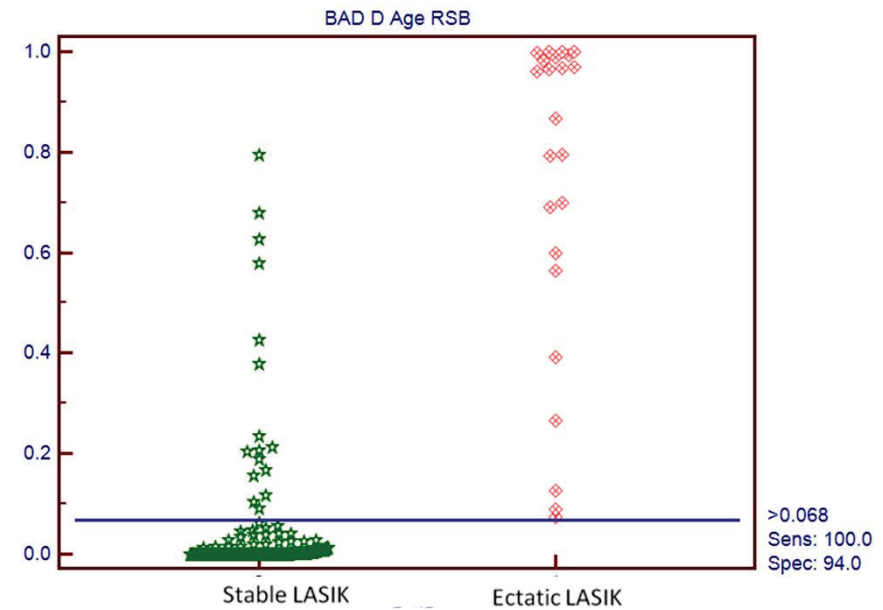

Figure 2: Dot diagram for the Ectasia Susceptibility Score (ESS-I) combined function of age, RSB and BAD-D

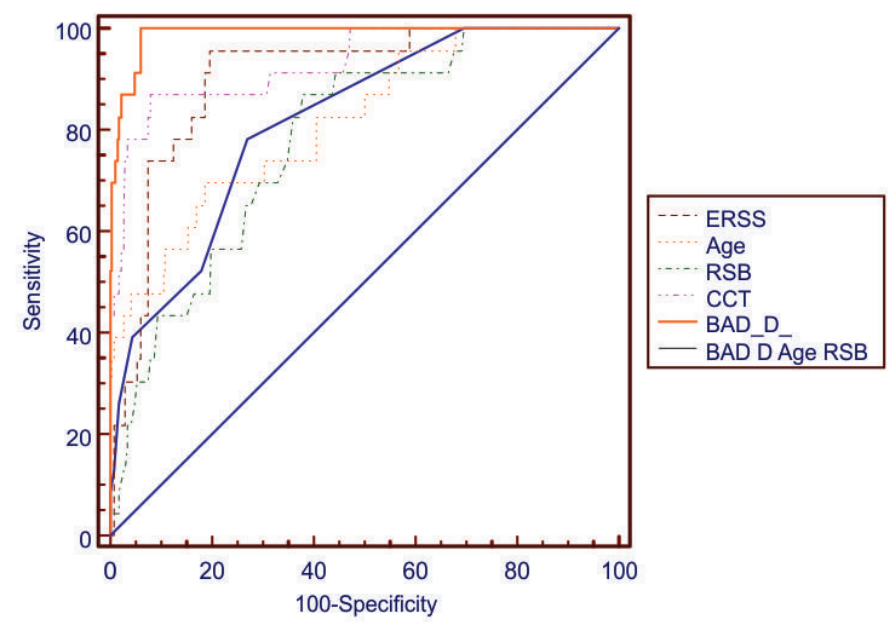

Figure 3: Comparison of ROC curves 
present study is considerably lower than the one (2.11) obtained for keratoconus with sensitivity of $99.59 \%(n=242$ eyes with clinical keratoconus) $)^{(6)}$. However, $87 \%$ sensitivity and $92 \%$ specificity are still not optimal and the need for further improvements beyond BAD-D for detecting ectasia susceptibility is recognized.

Screening for keratoconus is not the same as screening for eyes with higher susceptibility to develop keratectasia after LVC. Considering keratectasia occurs due to a state of biomechanical failure of the corneal stroma ${ }^{(3)}$, there are two possible distinct mechanisms for ectasia progression after LVC: 1 ) preoperative abnormally low (weak) biomechanical properties of the corneal stroma; 2) a severe biomechanical dwindling caused by the LVC procedure. For example, ectasia has been reported after surface ablation procedures ${ }^{(13)}$, but is much more common after LASIK, because the lamellar cut has an intrinsic biomechanical impact on the cornea ${ }^{(31)}$. Such impact varies accordingly to flap thickness ${ }^{(32)}$. Interestingly, there are reported cases of unilateral keratectasia after LASIK, while the fellow eye remained stable after photorefractive keratectomy (PRK) ${ }^{(33,35)}$.

In the present study, there was a statistically significant difference in the estimated RSB between ectatic and stable LASIK cases. However, no case with ectasia had an estimated RSB lower than $250 \mu \mathrm{m}$ ( minimal value $=269 \mu \mathrm{m})$. Imprecision of preoperative corneal pachymetry and variability of microkeratome cuts may impact accuracy of RSB prediction ${ }^{(36)}$. However, all cases had a Pentacam preoperative exam, allowing the calculation of the RSB from the thinnest point. In addition, all cases in the stable LASIK group and $69.57 \%$ of the ectatic cases had the lamellar cut performed by femtosecond laser, which has been demonstrated to have a relatively low variability on flap thickness 37 . The remaining $30.4 \%$ of the ectatic cases had flaps created by the Moria One Use-Plus microkeratome, which also has a low variability on flap thickness38. Thereby, the development of keratectasia in this series is less related to the biomechanical impact from the LVC procedure, but more related to an abnormal corneal structure that increased the risk for ectasia.

In this study, a logistic regression formula integrated age, RSB and BAD-D with a significant improvement in accuracy, leading to $100 \%$ sensitivity and $94 \%$ specificity. Logistic regression analysis has been used for predicting the outcome of a categorical dependent variable based on different predictor variables. Potential confounding between predictor variables is detected so that only the main effects are incorporated into the final formula. For example CCT was not selected for inclusion because it is already considered in the BAD-D calculation. The optimized formula provides the relative risk of developing ectasia as an Ectasia Susceptibility Score I (ESS-I; table 3). The logarithmic function leads to a binary outcome, with some overlapping results from zero to one. The cut off was 0.068 , which represent $6.8 \%$ relative risk. However, we propose that values higher than $5 \%$ should be considered moderate risk and values higher than $15 \%$ at high risk for ectasia progression after LVC.

The incorporation of age and RSB into the model, along with objective tomographic parameter BAD-D further customizes the risk assessment. This is also possible to consider certain risk levels in order to calculate the RSB needed, considering the BAD-D and age. For example, according to the ESS-I, a patient who is 21 years old with BAD-D of 0.9 and RSB of 350 would be at high risk of ectasia (24\%), and would require $\mathrm{RSB}$ of 398 for being at low risk (3\%). Another 21 years old patient with BAD-D of 0.2 would need RSB of 350 for being at low risk (3\%). A patient who is 42 years old with BAD-D of 0.9 would need RSB of 323 for having the ectasia risk under $3 \%$.

The major limitation of the present study is related to the relatively low number of ectasia cases. Also, the post-operative follow up of one year may not be sufficient, as late onset ectasia is possible ${ }^{(39,42)}$. Further follow up is needed for the stable group after LASIK, mainly in the subgroup detected as at higher risk based on the ESS-I. In such cases, careful long term evaluation for any corneal changes that might indicate a need for crosslinking, as well as patient advice against eye rubbing and other causes of eye trauma are necessary. Validation studies are also needed. These should include a series of cases with FFKC, but preferably cases that developed ectasia after LVC. In addition, improvements on the regression analysis with the incorporation of other parameters from Pentacam measurements are possible, as well as using different artificial intelligence strategies. These studies are underway.

\section{REFERENCES}

1. Seiler T, Quurke AW. Iatrogenic keratectasia after LASIK in a case of forme fruste keratoconus. J Cataract Refract Surg. 1998;24(7):1007-9.

2. Ambrósio R Jr,Wilson SE. Complications of laser in situ keratomileusis: etiology, prevention, and treatment. J Refract Surg. 2001;17(3):35079. Review.

3. Dawson DG, Randleman JB, Grossniklaus HE, O'Brien TP, Dubovy SR, Schmack I, et al. Corneal ectasia after excimer laser keratorefractive surgery: histopathology, ultrastructure, and pathophysiology. Ophthalmology. 2008; 115(12):2181-2191.e1.

4. Binder PS, Lindstrom RL, Stulting RD, Donnenfeld E, Wu H, McDonnell $\mathrm{P}$, et al. Keratoconus and corneal ectasia after LASIK. J Cataract Refract Surg. 2005;31(11):2035-8.

5. Ambrósio R Jr, Nogueira LP, Caldas DL, Fontes BM, Luz A, Cazal JO, et al. Evaluation of corneal shape and biomechanics before LASIK Int Ophthalmol Clin. 2011;51(2):11-38.

6. Ambrósio R Jr, Valbon BF, Faria-Correia F, Ramos I, Luz A. Scheimpflug imaging for laser refractive surgery. Curr Opin Ophthalmol. 2013;24(4):310-20. Review.

7. Ambrósio R Jr, Randleman JB. Screening for ectasia risk: what are we screening for and how should we screen for it? J Refract Surg. 2013;29(4):230-2.

8. Ambrósio R Jr, Klyce SD, Wilson SE. Corneal topographic and pachymetric screening of keratorefractive patients. J Refract Surg. 2003;19(1):24-9.

9. Amoils SP, Deist MB, Gous P, Amoils PM. Iatrogenic keratectasia after laser in situ keratomileusis for less than -4.0 to -7.0 diopters of myopia. J Cataract Refract Surg. 2000;26(7):967-77.

10. Klein SR, Epstein RJ, Randleman JB, Stulting RD. Corneal ectasia after laser in situ keratomileusis in patients without apparent preoperative risk factors. Cornea. 2006;25(4):388-403.

11. Ambrósio R Jr, Dawson DG, Salomão M, Guerra FP, Caiado AL, Belin MW. Corneal ectasia after LASIK despite low preoperative risk: tomographic and biomechanical findings in the unoperated, stable, fellow eye. J Refract Surg. 2010;26(11):906-11.

12. Tabbara KF, Kotb AA. Risk factors for corneal ectasia after LASIK. Ophthalmology. 2006;113(9):1618-22.

13. Randleman JB, Woodward M,Lynn MJ, Stulting RD. Risk assessment for ectasia after corneal refractive surgery. Ophthalmology. 2008;115(1):37-50.

14. Randleman JB, Trattler WB, Stulting RD. Validation of the Ectasia Risk Score System for preoperative laser in situ keratomileusis screening. Am J Ophthalmol. 2008;145(5):813-8.

15. Spadea L, Cantera E, Cortes M, Conocchia NE, Stewart CW. Corneal ectasia after myopic laser in situ keratomileusis: a long-term study. Clin Ophthalmol. 2012;6:1801-13.

16. Ramos IC, Correa R, Guerra FP, Trattler W, Belin MW, Klyce SD, et al. Variability of Subjective Classifications of Corneal Topography Maps 
From LASIK Candidates. J Refract Surg. 2013:1-7.

17. Chan CC,Hodge C,Sutton G. External analysis of the Randleman Ectasia Risk Factor Score System: a review of 36 cases of post LASIK ectasia. Clin Experiment Ophthalmol. 2010;38(4):335-40.

18. Duffey RJ,Hardten DR, Lindstrom RL, Probst LE, Schanzlin DJ,Tate $\mathrm{GW}$, et al. Ectasia after refractive surgery. Ophthalmology. 2008;115(10):1849; autor reply 1849-50.

19. Binder PS, Trattler WB. Evaluation of a risk factor scoring system for corneal ectasia after LASIK in eyes with normal topography. J Refract Surg. 2010;26(4):241-50.

20. Ambrósio R Jr, Belin MW. Imaging of the cornea: topography vs tomography. J Refract Surg. 2010;26(11):847-9.

21. Salomão MQ, Esposito A, Dupps WJ Jr. Advances in anterior segment imaging and analysis. Curr Opin Ophthalmol. 2009;20(4):32432. Review.

22. Ambrósio R Jr, Caiado AL, Guerra FP, Louzada R, Roy AS, Luz A, et al. Novel pachymetric parameters based on corneal tomography for diagnosing keratoconus. J Refract Surg. 2011;27(10):753-8.

23. Ambrósio R Jr, Dawson DG, Salomão M, Guerra FP, Caiado AL, Belin MW. Corneal ectasia after LASIK despite low preoperative risk: tomographic and biomechanical findings in the unoperated, stable, fellow eye. J Refract Surg. 2010;26(11):906-11.

24. Luz A, Ursulio M, Castañeda D, Ambrósio R Jr. [Corneal thickness progression from the thinnest point to the limbus: study based on a normal and a keratoconus population to create reference values]. Arq Bras Oftalmol. 2006;69(4):579-83. Portuguese.

25. Ambrósio R Jr,Alonso RS, Luz A, Coca Velarde LG. Corneal-thickness spatial profile and corneal-volume distribution: tomographic indices to detect keratoconus. J Cataract Refract Surg. 2006;32(11):1851-9.

26. Belin MW, Khachikian SS. An introduction to understanding elevation-based topography: how elevation data are displayed - a review. Clin Experiment Ophthalmol. 2009;37(1):14-29. Review.

27. Belin MW, Ambrósio R. Scheimpflug imaging for keratoconus and ectatic disease. Indian J Ophthalmol. 2013;61(8):401-6.

28. Valbon BF, Salomão M, Ramos I, Canedo AL, Nogueira L, Ambrósio Jr R. Importância da tomografia de córnea para o diagnóstico de ectasia. Rev Bras Oftalmol. 2012;71(5):302-8.

29. Valbon BdF, Santos RT, Ramos I, Canedo AL, Nogueira L, Ambrósio Jr. R. [Simplifying ectasia screening with corneal and anterior segment tomography]. Rev Bras Oftalmol. 2013;72(1):54-8. Portuguese.

30. Yoo SH, Cabot F, Gatinel D, Ambrósio R Jr, Goldich Y, ZareiGhanavati S. Refractive surgical problem: January consultation. J Cataract Refract Surg. 2013;39(1):148-52.

31. Dupps WJ Jr, Wilson SE. Biomechanics and wound healing in the cornea. Exp Eye Res. 2006;83(4):709-20. Review.
32. Medeiros FW, Sinha-Roy A, Alves MR, Dupps WJ Jr. Biomechanical corneal changes induced by different flap thickness created by femtosecond laser. Clinics (Sao Paulo). 2011;66(6):1067-71.

33. Kymionis GD, Tsiklis N, Karp CL, Kalyvianaki M, Pallikaris AI. Unilateral corneal ectasia after laser in situ keratomileusis in a patient with uncomplicated photorefractive keratectomy in the fellow eye. J Cataract Refract Surg. 2007;33(5):859-61.

34. Hodge C, Lawless M, Sutton G. Keratectasia following LASIK in a patient with uncomplicated PRK in the fellow eye. J Cataract Refract Surg. 2011;37(3):603-7.

35. Javadi MA, Mohammadpour M, Rabei HM. Keratectasia after LASIK but not after PRK in one patient. J Refract Surg. 2006;22(8):817-20.

36. Cheng HC, Chen YT, Yeh SI, Yau CW. Errors of residual stromal thickness estimation in LASIK. Ophthalmic Surg Lasers Imaging. 2008;39(2):107-13.

37. Slade SG, Durrie DS, Binder PS. A prospective, contralateral eye study comparing thin-flap LASIK (sub-Bowman keratomileusis) with photorefractive keratectomy. Ophthalmology. 2009;116(6):1075-82.

38. Du S, Lian J,Zhang L, Ye S, Dong S. Flap thickness variation with 3 types of microkeratome heads. J Cataract Refract Surg. 2011;37(1):144-8.

39. Hafezi F, Koller T, Derhartunian V, Seiler T. Pregnancy may trigger late onset of keratectasia after LASIK. J Refract Surg. 2012;28(4):242-3.

40. Zalentein WN, Tervo TM, Holopainen JM. Seven-year follow-up of LASIK for myopia. J Refract Surg. 2009;25(3):312-8.

41. Kymionis GD. Late bilateral keratectasia after LASIK in a low myopia patient. J Refract Surg. 2006;22(5):429-30; author reply 430.

42. Lifshitz T, Levy J, Klemperer I, Levinger S. Late bilateral keratectasia after LASIK in a low myopic patient. J Refract Surg. 2005;21(5):494-6.

\section{Author correspondence:}

Renato Ambrósio Jr.

Rua Conde de Bonfim, 211 - apto. 712

Zip Code 20520-050 - Rio de Janeiro (RJ), Brazil

Phone: 55 (21) 2234-4233

E-mail: dr.renatoAmbrósio@gmail.com 